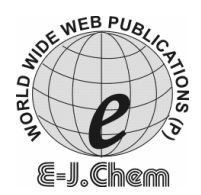

http://www.e-journals.net
ISSN: 0973-4945; CODEN ECJHAO

E-Journal of Chemistry

Vol. 5, No.4, pp. 832-837, October 2008

\title{
Effect of Temperature on Oscillatory Behaviour of the System Containing Isomers of Hydroxybenzoic Acid in Batch Reactor
}

\author{
MASOOD. A. NATH*, NADEEM B.GANAIE, \\ R. P. RASTOGI and G. M. PEERZADA \\ Department of Chemistry, \\ University of Kashmir, \\ Srinagar-190006 (J \& K) - India. \\ nath_masood@yahoo.co.in
}

Received 18 March 2008; Accepted 10 May 2008

\begin{abstract}
In the present paper a thorough study of temperature dependence on oscillatory behaviour of the Belousov-Zhabotinsky (BZ) system containing the isomers of hydroxybenzoic acids $+\mathrm{BrO}_{3}^{-}+\mathrm{Mn}(\mathrm{II})$ in aqueous acid medium $\left(1.0 \mathrm{M} \mathrm{H}_{2} \mathrm{SO}_{4}\right)$ at a fixed concentration of reacting species has been reported. On varying temperature, the oscillatory parameters like induction time, time period and number of oscillations show marked changes. These changes arise due to the position and number of hydroxyl groups in these isomers which affect the oscillations. Experimental observations have satisfactorily been explained by FKN mechanism and kinetic parameters. The oscillatory characteristics depend on the temperature dependence of the rate constant of the reaction controlling the inhibitory reaction steps (negative feedback).
\end{abstract}

Keywords; Hydroxybenzoic acid, BZ, Oscillatory behaviour, Batch Reactor

\section{Introduction}

Belousov-Zhabotinsky reaction ${ }^{1-3}$ is one of the most studied reactions which show oscillatory behaviour. Such an oscillatory behaviour could be generated by using a single or mixed substrates ${ }^{4-6}$. The organic substrates used can be aliphatic or aromatic compounds such as polyphenols and aniline derivatives. The oxidation of aliphatic compounds such as malonic acid or citric acid by bromate ion in acidified solution containing ceric ions (known as classical B-Z reaction) shows considerable interest, both experimentally ${ }^{7}$ and theoretically ${ }^{8,9}$. This interest is clearly prompted by the observation that in this reaction the 
concentration of bromide ion and redox ratio $\left(\log \left\{\left[\mathrm{Ce}^{\mathrm{IV}}\right] /\left[\mathrm{Ce}^{\mathrm{III}}\right]\right\}\right)$ oscillate with surprising regularity, at least after an induction period ${ }^{10}$. In summary, this oscillating reaction involves three important stages. In the first stage, bromide ions are consumed by reaction with either bromate ions or bromous acid. When concentration of bromide ions fall below a critical value, an autocatalytic reaction in a second stage takes over. Here one mole of bromous acid produced, in a reaction with bromate ions, two moles of bromous acid with concomitant oxidation of $\mathrm{Ce}(\mathrm{III})$ to $\mathrm{Ce}(\mathrm{IV})$. In the third stage, $\mathrm{Ce}(\mathrm{IV})$ ions oxidize malonic acid (as bromomalonic acid) forming $\mathrm{Ce}(\mathrm{III})$ and liberating bromide ions. As a result, the overall reaction is switched back to the first stage. Thus the cerium redox couple is a catalyst for the reaction. In a similar manner, uncatalysed oscillatory reactions, initially started by Orban, Koros and Noyes, developed a keen interest. Orban and Koros ${ }^{11}$, in 1978 discovered oscillations in redox potential ,bromide ion concentration and color in a system containing only sulphuric acid, bromate and organic species such as gallic acid $(3,4,5$ trihydroxybenzoic acid). This was the first class known as uncatalyzed B-Z oscillators ${ }^{12}$ which now includes 23 other organic substrates ${ }^{13-14}$. The oscillatory behaviour of uncatalyzed bromate oscillators have been explained in terms of OKN mechanism (a modification of FKN mechanism) Numerical simulations based on this mechanism by Herbine and Field ${ }^{15}$ reproduced the main features of uncatalyzed oscillations. Extended models were suggested by Liu and $\mathrm{Scott}^{16-17}$ and by Gyori et $a l^{18}$. A quinone derivative of the original organic reactant like gallic acid plays the role of metal ion catalyst. The mechanism of uncatalysed systems is similar to FKN mechanism but it is important to note that the process $\mathrm{B}$ in $\mathrm{FKN}$ mechanism is modified in this by the replacement of the reaction, $\mathrm{BrO}_{2}{ }^{\circ}+\mathrm{Ce}^{3+}+\mathrm{H}^{+} \leftrightarrow \mathrm{Ce}^{4+}+\mathrm{HBrO}_{2}$ (the metal ion oxidation by $\mathrm{BrO}_{2}{ }^{\circ}$ ) by $\mathrm{BrO}_{2}{ }^{\circ}+\mathrm{C}_{6} \mathrm{H}_{5}-\mathrm{OH}$ $\leftrightarrow \mathrm{HBrO}_{2}+\mathrm{C}_{6} \mathrm{H}_{5}-\mathrm{O}^{\circ}$

FKN mechanism has been found to be satisfactory on the basis of experimental studies on the $\mathrm{B}-\mathrm{Z}$ reaction and computer modeling. The hard core of the control mechanism for generation is;

(a) Positive feedback (autocatalysis),

$\mathrm{BrO}_{3}^{-}+\mathrm{HBrO}_{2}+3 \mathrm{H}^{+}+2 \mathrm{Ce}^{3+} \rightarrow 2 \mathrm{HBrO}_{2}+2 \mathrm{Ce}^{4+}+\mathrm{H}_{2} \mathrm{O}$

(b) Negative feedback (inhibitory reaction), $\mathrm{HBrO}_{2}+\mathrm{Br}^{-}+\mathrm{H}^{+} \rightarrow 2 \mathrm{HOBr}$

There are other steps in the mechanism involving $\mathrm{HBrO}_{2}, \mathrm{BrO}_{2}{ }^{\circ}, \mathrm{HOBr}, \mathrm{Br}^{-}$etc.

In view of the fact that the rate constant of the reaction in the negative feedback is of much smaller magnitude, it is expected that inhibitory reaction is most likely influencing oscillatory characteristics such as induction time $\left(\mathrm{I}_{\mathrm{p}}\right)$, time period $\left(\mathrm{t}_{\mathrm{p}}\right)$ and life time $\left(\mathrm{t}_{1}\right)$. In order to test this point, detailed experimental studies were undertaken with,

i) Organic substrates such as isomers of hydroxybenzoic acid,

ii) Catalysts such as $\mathrm{Mn}$ (II) and

iii) Temperature.

Since all these are expected to affect the rate of bromination of the substrate and subsequent release of $\mathrm{Br}^{-}$on oxidation of the bromoderivatives. There are several reports on the effect of temperature on oscillating chemical reaction when studied under batch conditions $^{19-21}$ or in $\mathrm{CSTR}^{22}$. In the present communication, the effect of temperature has been studied in depth. Organic substrates having different position and number of $-\mathrm{OH}$ groups have been chosen for detailed study, since the number and position of $-\mathrm{OH}$ groups influence the feasibility of bromination. 


\section{Experimental}

All reagents were either analytical grade chemicals or chemicals of high purity. The chemicals used are para-hydroxybenzoic acid ( $p$ HBA) [Himedia], meta-hydroxybenzoic acid (mHBA) [Himedia]. ortho-hydroxybenzoic acid (oHBA) [Qualigens], 3,4dihydroxybenzoic acid (3,4DHBA) [Fluka], 3,4,5-trihydroxybenzoic acid (gallic acid) [SRL], polymeric 3,4,5 trihydroxyhenzoic acid (tannic acid) [Excel-R], manganous sulphate monohydrate $[\mathrm{BDH}]$ and potassium bromate [Merck]. All the desired solutions were prepared in $1.0 \mathrm{M}$ sulphuric acid [Merck] of $98 \%$ purity.

The ion-meter (Eutech instruments Model PC-5500) having $\mathrm{pH}$ as well as $\mathrm{mV}$ option was setup in order to record change in $\mathrm{mV}$ versus time for the reaction systems. The reaction system comprising of any one of the aforesaid organic substrates, potassium bromate and $\mathrm{Mn}$ (II) solution was taken in one of the half cells into which a platinum electrode was dipped as the indicator electrode, whereas calomel electrode was taken as the reference electrode (SCE) in another half cell, containing $2.5 \times 10^{-4} \mathrm{M}$ solutions of potassium nitrate. The two half cells were connected through a salt bridge and kept immersed in a high precision water bath (Jindal-S.M.Scientific instruments) set up at desired temperature $\left(35 \pm 0.2^{0} \mathrm{C}\right)$. The potential change in $\mathrm{mV}$ was recorded after every ten or five seconds whichever was easy to monitor.

\section{Results and Discussion}

The observed oscillations of the different isomers of hydroxybenzoic acid are depicted in Figure 1 and the oscillatory parameters obtained are recorded in Table 1 . The reaction systems with different isomers of hydroxybenzoic acid have been studied at various temperatures viz; $30^{\circ}, 35^{\circ}, 40^{\circ}, 45^{\circ}$ and $50^{\circ} \pm 0.2^{\circ} \mathrm{C}$. From the data it is clear that the frequency of oscillations increase with the increase in temperature thereby reducing the oscillatory characteristics such as time of initiation $\left(t_{i n}\right)$ and time period $\left(t_{p}\right)$. The least square fit straight line equation favours our data by the following equation as;

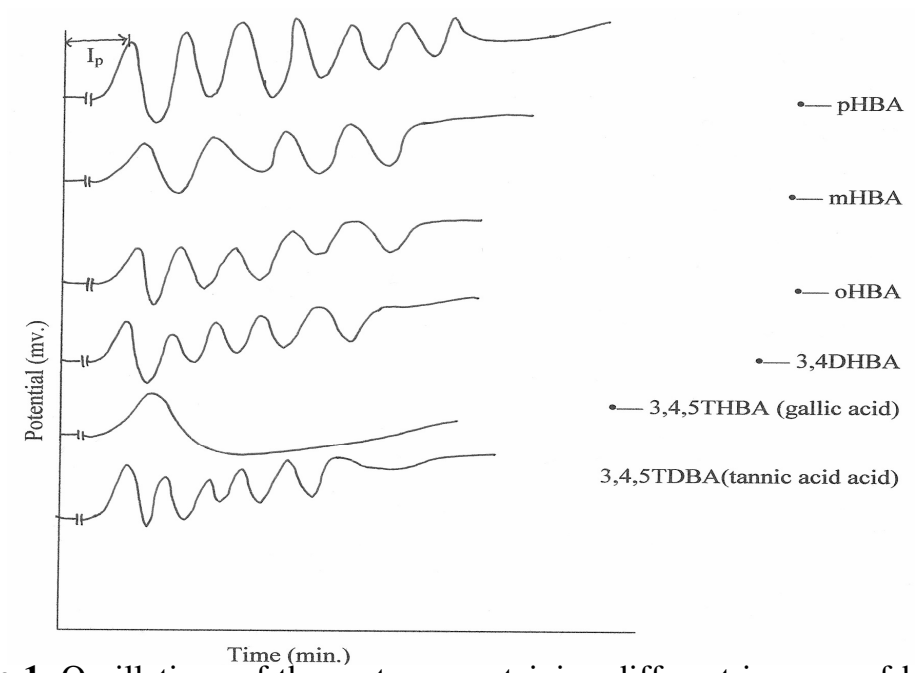

Figure 1. Oscillations of the systems containing different isomers of hydroxybenzoic acid$[\mathrm{HBA}]=0.0070 \mathrm{M}$ each; $\left[\mathrm{BrO}_{3}{ }^{-}\right]=0.0750 \mathrm{M} ;\left[\mathrm{Mn}^{2+}\right]=0.008 \mathrm{M} ;\left[\mathrm{H}_{2} \mathrm{SO}_{4}\right]=1.0 \mathrm{M}$; Temperature $=35^{\circ} \pm 0.2^{\circ} \mathrm{C}$. 
Table 1. Oscillatory parameters of the system with different isomers of hydroxybenzoic acid- $[\mathrm{HBA}]=0.0070 \mathrm{M}$ each; $\left[\mathrm{BrO}_{3}{ }^{-}\right]=0.0750 \mathrm{M} ;\left[\mathrm{Mn}^{2+}\right]=0.0080 \mathrm{M} ;\left[\mathrm{H}_{2} \mathrm{SO}_{4}\right]=1.0 \mathrm{M}$; Temperature $=35^{\circ} \pm 0.2^{\circ} \mathrm{C}$.

\begin{tabular}{|c|c|c|c|c|c|c|c|c|c|c|c|c|}
\hline \multirow{3}{*}{$\begin{array}{l}\text { Temp } \\
{ }^{0} \mathrm{C} \\
( \pm 0.2)\end{array}$} & \multicolumn{12}{|c|}{ Organic substrate } \\
\hline & \multicolumn{3}{|c|}{$p \mathrm{HBA}$} & \multicolumn{2}{|c|}{$o \mathrm{HBA}$} & \multirow{2}{*}{$\frac{m \mathrm{HBA}}{\mathrm{t}_{\mathrm{p}}}$} & \multicolumn{2}{|c|}{$3,4 \mathrm{DHBA}$} & \multirow{2}{*}{$\begin{array}{c}\text { Gallic } \\
\text { acid }\end{array}$} & \multicolumn{3}{|c|}{ Tannic acid } \\
\hline & $t_{\text {in }}$ & $t_{p}$ & $\mathrm{t}_{\text {in }}$ & $t_{p}$ & $t_{\text {in }}$ & & $t_{\text {in }}$ & $t_{p}$ & & $t_{p}$ & $\mathrm{t}_{\mathrm{in}}$ & $t_{p}$ \\
\hline 30 & 2.00 & 5.50 & 2.16 & 7.16 & 2.83 & 9.00 & 2.50 & 5.70 & $*$ & $*$ & 2.50 & 3.50 \\
\hline 35 & 1.33 & 2.70 & 1.66 & 5.70 & 2.33 & 7.66 & 1.83 & 4.16 & $*$ & $*$ & 2.00 & 1.00 \\
\hline 40 & 1.00 & 2.50 & 1.16 & 3.00 & 1.32 & 6.33 & 1.66 & 1.66 & $>10$ & * & 0.50 & 0.66 \\
\hline 45 & 0.66 & 1.00 & 0.83 & 2.50 & 1.00 & 3.00 & 1.33 & 1.33 & 1.50 & $*$ & 0.33 & $* *$ \\
\hline 50 & 0.50 & 0.50 & 0.66 & 2.00 & 0.83 & 2.66 & 1.00 & 0.66 & 1.16 & $*$ & 0.16 & $* *$ \\
\hline
\end{tabular}

* indicates the value is very large and ** very small hence difficult to calculate.

$$
\begin{aligned}
& t_{\text {in }} \infty \frac{1}{k} \\
& \text { or } t_{\text {in }}=\frac{\alpha}{k}
\end{aligned}
$$

where $\alpha$ is constant

Using Arrhenius equation, $k=A \cdot e^{E / R T}$, equation(2) becomes

$$
\begin{gathered}
t_{i n}=\frac{\alpha}{k} \cdot \mathrm{e}^{\mathrm{E} / \mathrm{RT}} \\
\text { or } t_{i n}=\text { cons } \tan t \cdot e^{E / R T} \\
\text { or } \log t_{i n}=\log \text { cons } \tan t+\left[\frac{\mathrm{E}}{\mathrm{R}}\right] \times \frac{1}{\mathrm{~T}}
\end{gathered}
$$

where, $\mathrm{A}$ is pre-exponential factor, $\mathrm{E}$ is effective energy of activation, $\mathrm{R}$ is gas constant and $\mathrm{T}$ is absolute temperature.

For confirming the above explanation $\log t_{\text {in }}$ has been plotted against 1/T in Figure 2 and the slope of the straight line yields the effective activation energy and not the actual activation energy. The constant $\mathrm{k}$ is rate constant of the slowest reaction and the net rate of the reaction would be governed by the slowest step. Authors considered chemical oscillation as a monomolecular process by assuming the reciprocal of time period at initial concentrations as a first order rate constant $\mathrm{t}^{23-25}$ and calculated activation parameters such as enthalpy of activation $\left(\Delta \mathrm{H}^{\#}\right)$ and entropy of activation $\left(\Delta \mathrm{S}^{\#}\right)$ and activation energy from logarithmic form of Eyring's equation. But we have not mentioned such parameters. This is because oscillating chemical reactions are very complex and involve large number of steps having high rate constant values, calculated experimentally by Field and Burger and verified by computer simulations. Therefore the rate constant and activation energy in their work may not be accurate because of complexity in the system. 


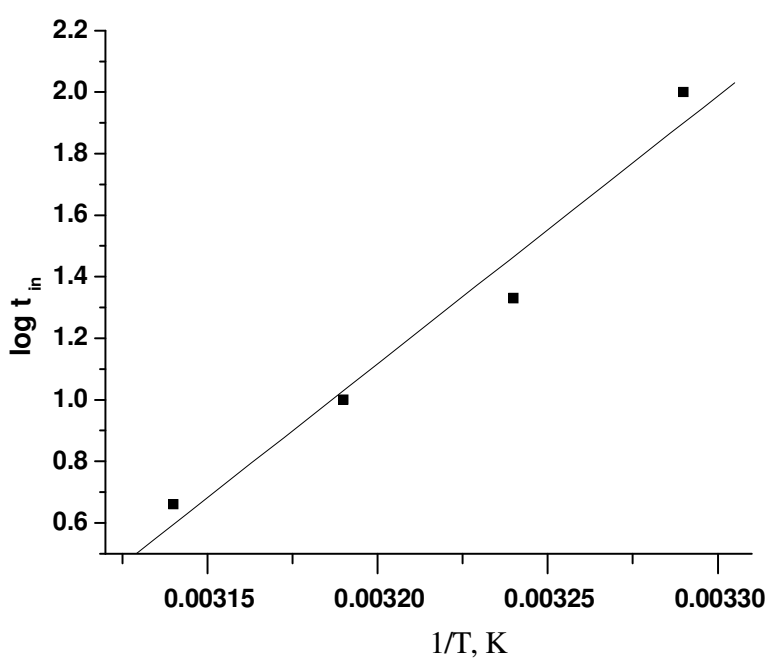

Figure 2. Linear dependence of $\log \mathrm{t}_{\mathrm{in}}$ versus $1 / \mathrm{T}$ for the various isomers of hydroxybenzoic acid.

From the mechanistic point of view, the FKN mechanism seems to be satisfactorily consistent with our system. The low induction time is due to the fast bromination reaction of hydroxybenzoic acids to form corresponding bromoderivatives. The rate of bromination increases with the increase in temperature thereby decreasing the induction time. Out of monohydroxybenzoic acids, para isomer has lesser induction period than ortho or meta isomer. The reason being, $p$-HBA undergoes bromination reaction very quickly owing to the fact that bromine occupies the position ortho to $-\mathrm{OH}$ group and meta to $-\mathrm{COOH}$ group, keeping in view that $-\mathrm{COOH}$ group is meta directing and - $\mathrm{OH}$ group is $o, p$ directing. However, ortho isomer should be more reactive, but because of intramolecular hydrogen bonding in the molecule there arises the problem of solubility in aqueous acid medium. However, on slight heating its solubility increases and hence can work as a chemical oscillator. Further, on comparing monohydroxybenzoic acids with di- and trihydroxy benzoic acids such as 3, 4 dihydroxybenzoic acid and gallic acid, again, the parahydroxybenzoic acid seems to be more reactive than 3,4-DHBA and gallic acid. It is important to note that for all the isomers, $\mathrm{Mn}(\mathrm{II})$ is used as catalyst. However, gallic acid shows better oscillations in presence of $\mathrm{Ce}(\mathrm{IV})$ or $\mathrm{Fe}(\mathrm{II})$ and in mixed substrate systems. Tannic acid, a resinous polymeric trihydroxybenzoic acid shows excellent oscillations of high frequency than gallic acid. This is due to the presence of large number of free hydroxyl groups which activate the position for bromination to occur.

\section{Conclusion}

From the present investigation, the following conclusion can be drawn

- With the increase in temperature oscillatory parameters such as $t_{i n}$ and $t_{p}$ decreases, this results an increase in the rate of reaction.

- The order of reactivity of different isomers of hydroxybenzoic acid can be predicted depending upon the rate of bromination reaction.

- The experimental findings are in consistence with the linear fit equation. 


\section{References}

1. Field R J, Burger M, Oscillations and Traveling waves in Chemical Systems; Wiley Interscience: New York,1985.

2. Belousov B P 1958, Collection of Abstracts on Radiation Medicine: Medgiz, Moscow 1959, p.145.

3. Zhabotinskii A M, Biophysics, 1964, 9, 306.

4. Dutt A K and Banerjee R S, Chem Phys Lett., 1983, 99, 186.

5. Lalitha P V and Ramaswamy R, React. Kinet Catal Lett., 1992, 47, 133.

6. Rastogi R P and Misra G P, Indian J Chem., (A).1990, 29, 1205.

7. Pacault A, Kepper P and Hanusse P, Comptes. Rendus, 1975, 280, 157.

8. $\quad$ Turner J S, Physics Letters, 1976, 56A, 1955.

9. Field R J, J Chem Phys., 1975, 63, 2289.

10. Field R J, Koros E and Noyes R M, J Am Chem Soc., 1972, 94, 8649.

11. Koros E and Orban M, Nature, (London), 1978, 273, 371.

12. Noyes R M, J Am Chem Soc., 1980, 102, 4644.

13. Orban M and Koros E, J Phys Chem., 1978, 82, 1672.

14. Srivastava P K, J Indian Chem Soc., 1989, 66, 304.

15. Herbine P and Field R J, J Phys Chem., 1980, 84, 1330.

16. Liu J and Scott S K, J. Chem. Soc., Faraday Trans., 1991, 87, 2135

17. Liu J and Scott S K, J Chem Soc., Faraday Trans., 1992, 88, 909.

18. Gyori L, Varga M, Koros E, Field R J and Ruoff P, J Phys Chem., 1989, 93, 2836.

19. Dutt A K and Banerjee R S, Chem. Phys Lett., 1983, 99, 186.

20. Rastogi R P, Syal V and Misra G P, Indian J Chem., (A), 1991, 30, 203.

21. Rastogi R P, Syal V and Misra G P, Indian J Chem., (A).1991, 30, 203.

22. Kulkarni V R, Basavaraja C and Vishnuvardhan T K, J Indian Chem Soc., 2003, 80, 100.

23. Ganapathisubraminium N, Jaya S and Ramaswamy R, Curr Sci., 1978, 47, 770.

24. Dutt A K and Banerjee R S, Sci Cult.,1985, 51, 408.

25. Pal S C and Banerjee R S, J Indian Chem Soc., 1996, 73, 659. 


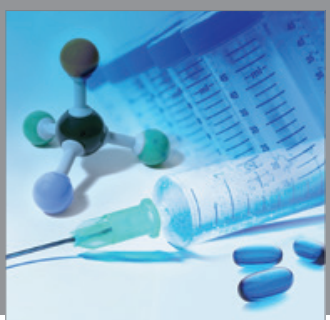

International Journal of

Medicinal Chemistry

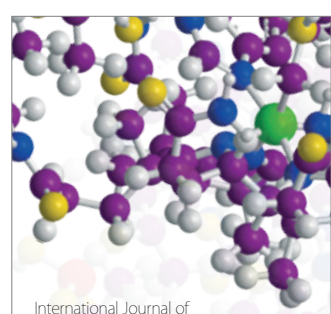

Carbohydrate Chemistry

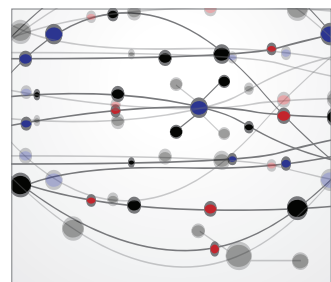

The Scientific World Journal
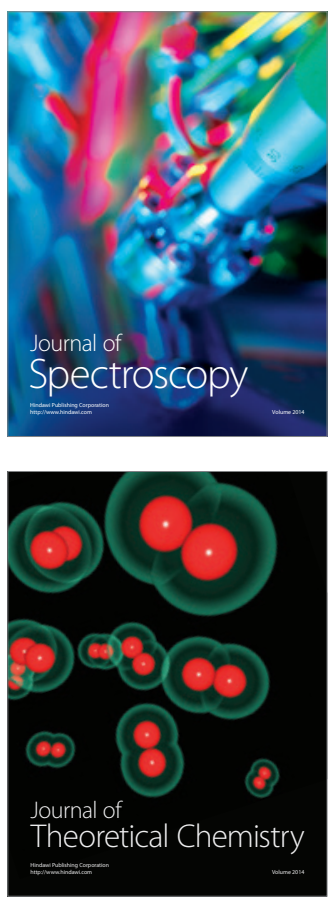
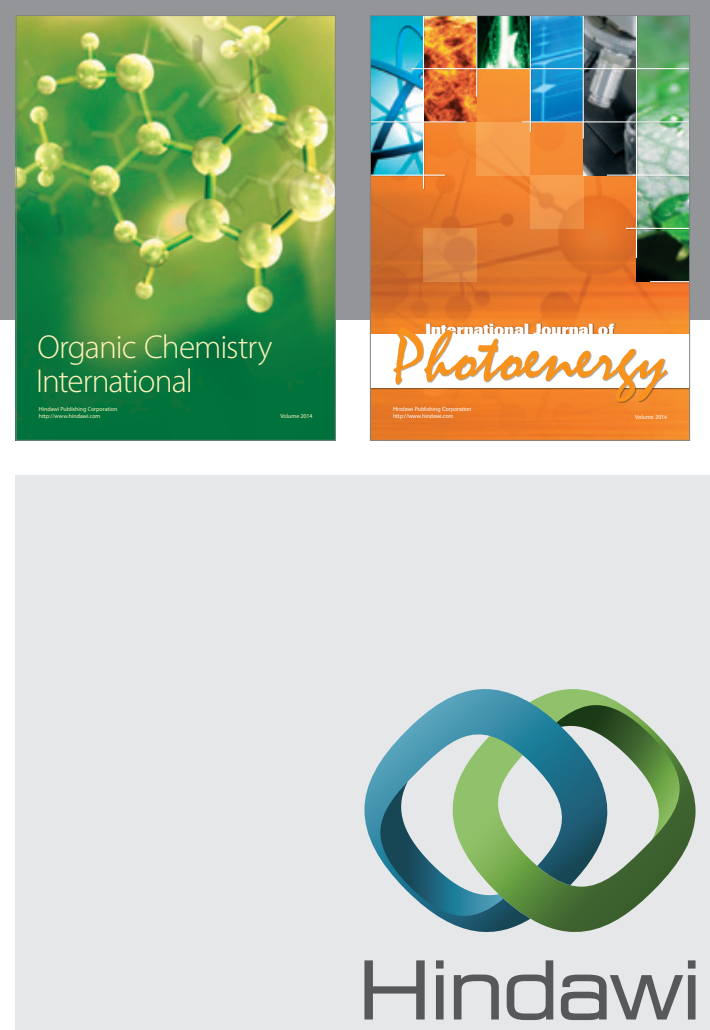

Submit your manuscripts at

http://www.hindawi.com
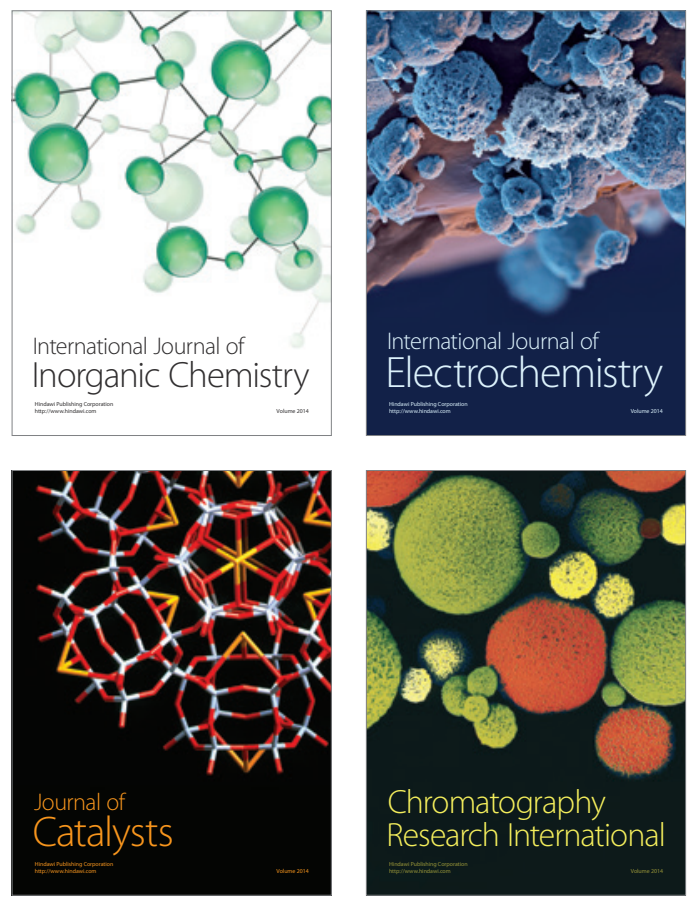
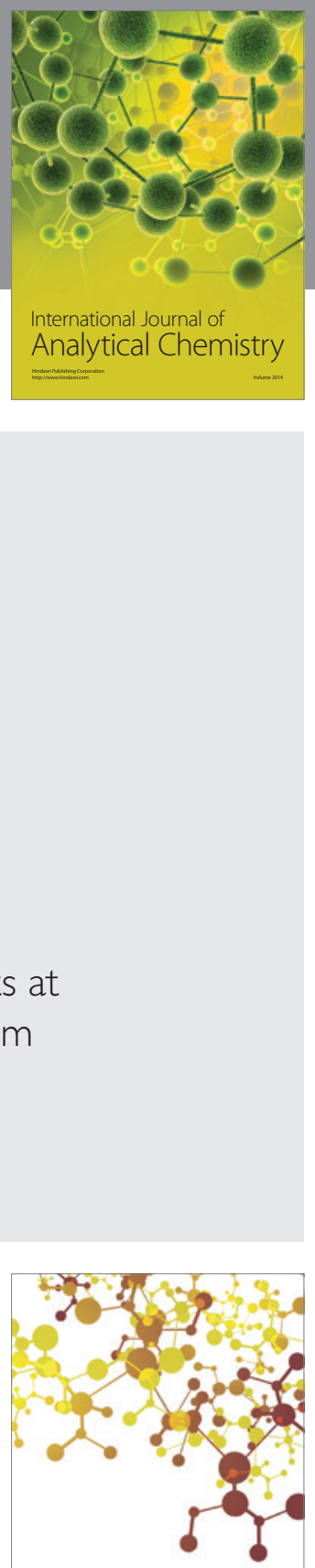

Journal of

Applied Chemistry
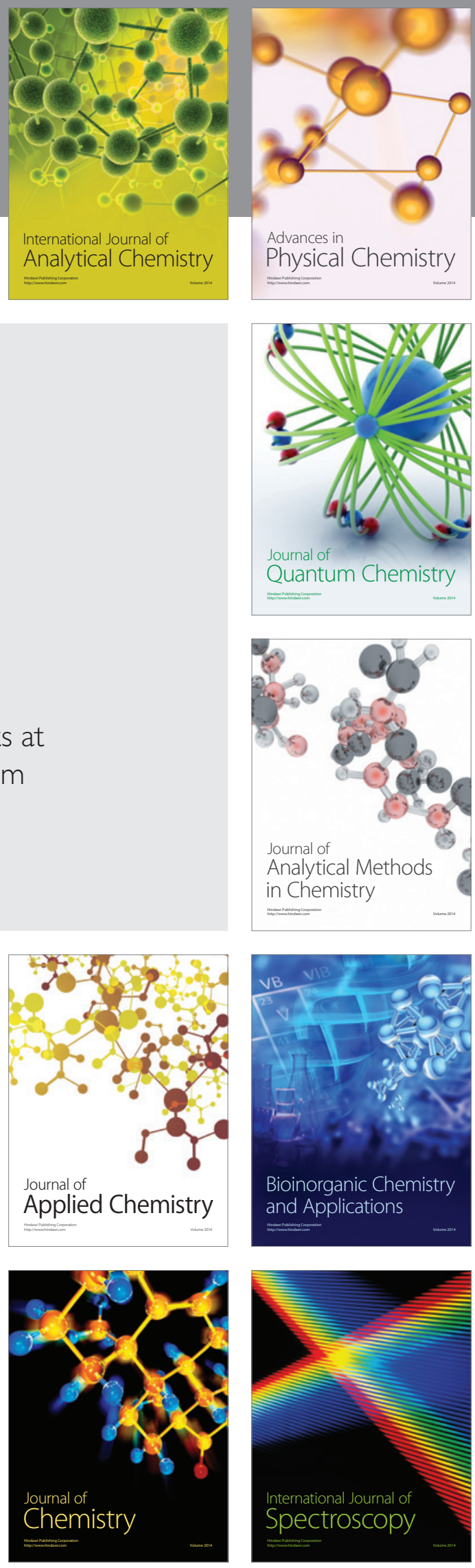